\section{Assessment of illness severity in community acquired pneumonia: a useful new prediction tool?}

\section{Woodhead}

The clinical heterogeneity of CAP means that no severity scoring system will ever be able consistently to separate all patients into correct management subgroups, but the recently developed CURB-65 prediction tool appears to be an advance.

n llness severity might usefully guide a number of management decisions in the care pathway of a patient with community acquired pneumonia (CAP). Whether to refer to hospital by the primary care physician, whether to admit by the hospital junior doctor, what investigations to perform, what antibiotic(s) to give, and whether to admit to the intensive care unit (ICU) are just some examples. This approach is captured to a varying extent in a number of the published management guidelines for CAP. ${ }^{1-5}$ While a clinical prediction tool to assess severity might therefore be helpful, there is no agreement on what constitutes the best approach to this. Additional caveats are that such a tool would need to be better than current practice, would need to accurately do what it sets out to do (that is, predict outcome), would need to be simple to use in a variety of settings, would need to have been shown to alter outcomes, and would need to actually be usable in clinical practice.

That current practice is inadequate is suggested by a number of studies. The mortality rate of $5-10 \%$ of adults admitted to hospital is well recognised-some of these deaths might be preventable. Routine clinical judgement was found to underestimate illness severity in one study ${ }^{6}$ and another found illness severity assessment to be the most common failing in the management of young adults dying from $\mathrm{CAP}^{7}$ Severity assessment before ICU admission has been found to be suboptimal for a wide variety of conditions, ${ }^{8}$ and the variation in hospital $^{9-13}$ and ICU $^{14}$ admission rates for CAP is probably at least in part due to inaccurate severity assessment.

Approaches to severity assessment for CAP are slowly evolving. Early studies used prediction tools developed for other conditions such as the simplified acute physiology score (SAPS), APACHE, and appropriateness evaluation protocol
(AEP), but these were found to be impractical or less accurate than CAP specific tools. Subsequent studies have used three main approaches to the development of CAP specific tools, often directed towards single management decisions. The "British Thoracic Society (BTS) rule"15 sought to separate a severely ill group and was based on three (subsequently modified to four ${ }^{6}$ ) criteria available shortly after hospital admission. The American Thoracic Society (ATS) proposed the assessment of nine ${ }^{16}$ ( subsequently modified to five ${ }^{17}$ ) criteria for use in the identification of patients for whom admission to the ICU was to be considered. The Pneumonia Severity Index (PSI), based on 20 criteria, was developed to identify less severely ill patients who might safely be managed at home. ${ }^{18}$

In this issue of Thorax Lim et al ${ }^{19}$ describe the CURB- 65 severity prediction tool. They have used prospectively collected CAP databases that include a total of 1068 hospitalised adult patients from three primary care based healthcare systems to identify the most important prognostic factors associated with 30 day mortality. Based on the modified "BTS rule", a CURB (Confusion, blood Urea $>7 \mathrm{mmol} / \mathrm{l}$, Respiratory rate $\geqslant 30 / \mathrm{min}$, and low Blood pressure) severity score was calculated. Age $\geqslant 65$ remained independently associated with outcome and was added to create the six level CURB-65 score which was tested in a derivation cohort. A similar five level score (CRB-65), omitting blood urea and therefore applicable outside hospital, was also developed and tested. Both scores correlated with mortality, allowing the identification of patients at low, intermediate, and high risk of death.

Does this add to what we already know? The "BTS rule" has only been tested in small cohorts of patients and is poorly predictive in elderly patients. The modified "BTS rule" performs better but is limited to the separation of patients into only two categories-severely ill and not so severely ill. The "ATS score" depends on variables only available in hospital and has been primarily assessed against ICU admission as an end point. Neither score is useful for guiding all of the management decisions listed above and neither has been implemented prospectively in a study to change management. The new scores need only four (CRB65) or five (CURB-65) variables, based largely on clinical assessment, and facilitate the separation of patients into three management groups with mortalities ranging from $0 \%$ to $33 \%$ in the derivation cohort. The authors suggest that such grouping may inform the clinical decision as to whether to treat at home or admit to hospital, and whether to manage as severe or non-severe pneumonia. They are simple to use, can be used in a variety of settings, and allow good discrimination in the guidance of management decisions. Use of the same language across management boundaries from the primary care physician through the general medical physician to the intensive care physician is an additional potential benefit. The PSI also separates patients into five categories but it depends on many variables, some of which are only available in hospital, and the outcomes in categories I-III are similar. A recent study concluded that neither the BTS score, the ATS score, nor the PSI was adequately robust in severity prediction to be optimum for clinical practice. $^{14}$ However, this was based largely on the soft and variable end point of ICU admission .

The CURB-65 score now needs to be validated in other patient cohorts and tested prospectively to see if outcomes can be improved. There is some evidence that a severity based approach can reduce primarily cost related outcomes (such as length of hospital stay) which may be of qualitative value to the patient. ${ }^{20-23}$ However, other studies have not found reductions in length of stay ${ }^{24}$ or the potential to treat more at home. ${ }^{25}{ }^{26}$ Only one study has suggested a reduction in mortality. ${ }^{27}$ Such studies are difficult to design and conduct, but the CAPITAL study shows what might be done. ${ }^{21}$ In this site randomised study 10 hospitals using conventional practice were compared with nine others where a critical care pathway, including severity assessment with the PSI, was used. A reduction in the admission of low severity patients, the number of bed-days per patient, and the number of days of intravenous antibiotics was seen in the study hospitals. However, there was no difference in quality of life, complications, readmission, or mortality. This study design may be limited by secular changes in management practices in control hospitals. Such changes produced comparable improvement in control and study 
hospitals in trials of care pathways for various surgical procedures. ${ }^{28}$ The evidence that severity scoring tools can improve outcomes is largely based on North American healthcare systems which may or may not be translatable to other, especially primary care based, healthcare systems.

If the CURB-65 can be further validated and shown to alter outcomes, the final hurdle to be surmounted is its applicability to everyday practice as opposed to research studies. In this regard its simplicity and use of readily available factors hold promise. The readiness of local UK hospital guidelines to follow the BTS guidelines in using severity based treatment algorithms is also hopeful. ${ }^{29}$ However, local audits suggest a gap between these and current practice. ${ }^{30}$ While disease specific score systems might be more accurate, they may not be the most practical. It must not be forgotten that CAP is but one of many pulmonary and often nonpulmonary acute conditions that primary care physicians and junior hospital doctors have to deal with. How many disease specific scores can they cope with? Assessing illness severity usually translates into measurement of basic physiological parameters, regardless of the causative condition. CAP is no exception. While possibly less accurate, a simple generic score system based on such parameters might achieve wider clinical applicability if it was shown to have reasonable operating characteristics compared with the above scores. Such an early warning score (EWS) has been developed and shows some promise in acute medical admissions. ${ }^{31}$ It would be interesting to assess the performance of the EWS against CURB-65. Although in the future one can foresee the time when entry of the diagnosis of CAP into the electronic patient record might automatically generate a CURB-65 or other severity score, while we continue with paper records this may be more difficult.

The best assessment tool for CAP and whether different assessment tools scores might be applicable in different healthcare systems remains to be determined, but CURB-65 appears to be an advance. The clinical heterogeneity of CAP means that no scoring system will ever be able consistently to separate all patients into correct management subgroups. Factors other than illness severity will always influence some management decisions. Severity scoring systems must continue to be seen as a useful adjunct to, rather than a replacement for, the art of clinical practice.

Thorax 2003;58:371-372

\section{Author's affiliation}

M Woodhead, Consultant in General and Respiratory Medicine, Manchester Royal Infirmary, Oxford Road, Manchester M13 9WL; mark.woodhead@cmmc.nhs.uk

\section{REFERENCES}

1 British Thoracic Society. BTS guidelines for the management of community acquired pneumonia in adults. Thorax 2001;56/Suppl IV):iv1-64.

2 Bartlett JG, Dowell SF, Mandell LA, et al. Practice guidelines for the management of community-acquired pneumonia in adults. Infectious Diseases Society of America. Clin Infect Dis 2000;31:347-82.

3 European Study on Community-Acquired Pneumonia Committee. Guidelines for management of adult community-acquired lower respiratory tract infections. Eur Respir 1998;11:986-91.

4 Mandell LA, Marrie TJ, Grossman RF, et al. Canadian guidelines for the initial management of community-acquired pneumonia: an evidence-based update by the Canadian Infectious Diseases Society and the Canadian Thoracic Society. The Canadian Community-Acquired Pneumonia Working Group. Clin Infect Dis 2000;31:383-421.

5 Niederman MS, Mandell LA, Anzueto A, et al. Guidelines for the management of adults with community-acquired pneumonia. Diagnosis, assessment of severity, antimicrobial therapy, and prevention. Am J Respir Crit Care Med 2001; 163:1730-54.

6 Neill AM, Martin IR, Weir R, et al. Community-acquired pneumonia: aetiology and usefulness of severity criteria on admission. Thorax 1996:51:1010-16.

7 Tang CM, Macfarlane JT. Early management of younger adults dying of community-acquired pneumonia. Respir Med 1993;87:289-94

8 McQuillan $\mathbf{P}$, Pilkington S, Allan A, et al. Confidential inquiry into quality of care before admission to intensive care. $B M$ 1998;316: 1853-8 (published erratum appears in BM 1998;317:631).

9 Almirall J, Bolibar I, Vidal J, et al. Epidemiology of community-acquired pneumonia in adults: a population-based study. Eur Respir J 2000;15:757-63.

10 Bochud PY, Moser F, Erard P, et al. Community-acquired pneumonia. A prospective outpatient study. Medicine (Baltimore) 2001;80:75-87.

11 Jokinen C, Heiskanen L, Juvonen $\mathrm{H}$, et al. Incidence of community-acquired pneumonia in the population of four municipalities in Eastern Finland. Am J Epidemiol 1993;137:977-88.

12 Marrie TJ, Peeling RW, Fine M, et al. Ambulatory patients with community-acquired pneumonia: the frequency of atypical agents and clinical course. Am J Med 1996; 101:508-15.

13 Woodhead MA, Macfarlane JT, McCracken JS, et al. Prospective study of the aetiology and outcome of pneumonia in the community. Lancet 1987;i:671-4.

14 Angus DC, Marrie TJ, Obrosky DS, et al. Severe community-acquired pneumonia: use of intensive care services and evaluation of American and British Thoracic Society Diagnostic criteria. Am J Respir Crit Care Med 2002;166:717-23.

15 British Thoracic Society. Communityacquired pneumonia in adults in British hospitals in 1982-1983: a survey of aetiology, mortality, prognostic factors and outcome. Q J Med 1987;62:195-220.

16 American Thoracic Society. Guidelines for the initial management of adults with community-acquired pneumonia: diagnosis, assessment of severity, and initial antimicrobial therapy. Am Rev Respir Dis 1993;148:1418-26.

17 Ewig S, Ruiz M, Mensa J, et al. Severe community acquired pneumonia. Assessment of severity criteria. Am J Respir Crit Care Med 1998; 158:1102-8.

18 Fine MJ, Auble TE, Yealy DM, et al. A prediction rule to identify low-risk patients with community-acquired pneumonia. $N$ Engl J Med 1997;336:243-50.

19 Lim WS, van der Eerden MM, Laing R, et al. Defining community acquired pneumonia severity on presentation to hospital: an international derivation and validation study. Thorax 2002;58:377-82

20 Atlas SJ, Benzer TI, Borowsky LH, et al. Safely increasing the proportion of patients with community-acquired pneumonia treated as outpatients: an interventional trial. Arch Intern Med 1998; 158:1350-6.

21 Marrie TJ, Lau CY, Wheeler SL, et al. A controlled trial of a critical pathway for treatment of community-acquired pneumonia. CAPITAL Study Investigators.

Community-Acquired Pneumonia Intervention Trial Assessing Levofloxacin. JAMA 2000;283:749-55.

22 Suchyta MR, Dean NC, Narus S, et al. Effects of a practice guideline for community-acquired pneumonia in an outpatient setting. Am J Med 2001;110:306-9.

23 Meehan TP, Weingarten SR, Holmboe ES, et al. A statewide initiative to improve the care of hospitalized pneumonia patients: the Connecticut Pneumonia Pathway Project. Am J Med 2001:111:203-10.

24 Rhew DC, Riedinger MS, Sandhu M, et al. A prospective, multicenter study of a pneumonia practice guideline. Chest 1998;1 14:115-9.

25 Stauble SP, Reichlin S, Dieterle T, et al. Community-acquired pneumonia: which patients are hospitalised? Swiss Med Wkly 2001;131:188-92.

26 Marras TK, Gutierrez C, Chan CK. Applying a prediction rule to identify low-risk patients with community-acquired pneumonia. Chest 2000; 118: 1339-43.

27 Dean NC, Silver MP, Bateman KA, et al. Decreased mortality after implementation of a treatment guideline for community-acquired pneumonia. Am J Med 2001;1 10:451-7.

28 Pearson SD, Kleefield SF, Soukop JR, et al. Critical pathways intervention to reduce length of hospital stay. Am J Med 2001:110:175-80

29 Woodhead M, Macfarlane J. Local antibiotic guidelines for adult community-acquired pneumonia (CAP): a survey of UK hospital practice in 1999. J Antimicrob Chemother 2000;46:141-3.

30 West SK, King S. An audit of the management of community-acquired pneumonia in Southampton General Hospital. Thorax 2002;57(Suppl III):iii69.

31 Subbe CP, Kruger $M$, Rutherford $P$, et al Validation of a modified early warning score in medical admissions. Q J Med $2001 ; 94: 521-6$ 


\section{Patients with COPD: do we fail them from beginning to end?}

\section{R Partridge}

Respiratory physicians should take some responsibility for what could be regarded as the neglect of patients with COPD and need to raise the profile of the disease with governments and funding bodies. The aim is to prevent its cause, modify its natural history, focus research and ensure the implementation of all measures that may reduce the suffering.

n $n$ the UK 17500 men and 14500 women die every year from chronic obstructive pulmonary disease (COPD). Work reported in this issue of Thorax suggests that these figures are likely to be falsely low. ${ }^{1}$ The published death rate compares with 13000 women dying of breast cancer and 9500 men dying of prostate cancer every year. Both of the latter two diseases now attract much publicity, considerable research expenditure and, for breast cancer at least, a very expensive health service screening programme, the value of which is continually debated. Globally, COPD is the fourth or fifth leading cause of death and both morbidity and mortality are predicted to rise. The World Health Organisation (WHO) is one of the few organisations to have recognised the impending burden of this disease to both the individual and to society, publishing both a consultation document on the development of a comprehensive approach for the prevention and control of respiratory disease $\mathrm{e}^{2}$ and also an implementation strategy. ${ }^{3}$ At a national level few countries have health initiatives to help those with COPD, and perhaps the respiratory fraternity should take some responsibility for what could be regarded as the neglect of this group of patientsneglect not necessarily at the level of personal care, but neglect in terms of failure to ensure that governments and health departments resource the necessary care, and resource research into better management.

In what areas might we have failed these patients? "I started when it was fashionable doctor, and try as I might I have only now been able to give up when it's probably too late". This is a statement by a smoker which we all hear too often. Fifty years after Sir Richard Doll made clear the association between smoking and disease $e^{4}$ and 25 years after the late Charles Fletcher showed clearly the inexorable decline of airway function in susceptible smokers, ${ }^{5}$ we are only in 2003

beginning to take appropriate action to curb tobacco promotion-9 years after the UK Government's Chief Economist declared that banning tobacco advertising would be likely to save 3000 lives per annum and $£ 40$ million unnecessary NHS expenditure.

Recent work underlines the importance of action in this field by showing that a much higher proportion of smokers than was previously thought will develop COPD. ${ }^{6}$ However, the effect of European control and a decline in US smoking habits has merely led a deceitful and manipulative industry to peddle its noxious wares in low income countries ill equipped to cope with today's health burdens, without tomorrow's addition of COPD and lung cancer. In this field the WHO have been less successful and, despite valiant attempts, global tobacco control has reverted to becoming a dream because of the supremacy of vested interests.

Perhaps we can at least diagnose COPD early in its natural history and target smoking cessation advice at those yet to develop severe disease? In practice we again fail, and most patients present with severe symptomatic disease because of, among other factors, a lack of use of spirometry in primary care. Van Schayck and colleagues ${ }^{7}$ have shown how a trained practice assistant can target smokers in primary care and, especially by looking at those who are older with a cough, enable us to detect those with significant airway narrowing who may not have been diagnosed by their GP. These can then be exhorted to cease smoking with the expectation that their subsequent rate of decline will at least parallel that of a non-smoker. Even here there is evidence that we encourage smoking cessation but rarely give sufficient advice about how this may be achieved. ${ }^{\circ}$

What of those who miss our feeble attempts at screening? The majority present with established airway narrowing and with symptoms and limitation of activities. Apart from smoking cessation, we have no conclusive evidence that any therapeutic intervention reverses progressive decline in airway function. Inhaled bronchodilators have an essential role in relieving symptoms, and $\beta$ agonists, anticholinergic agents, and theophylline have all been shown to have some beneficial effect on exercise capacity and together may have a greater effect on airway function. ${ }^{9}$ Long acting inhaled $\beta$ agonists and once daily anticholinergic agents ${ }^{10}{ }^{11}$ may improve health status but the exact role of these agents and evaluation of their cost effectiveness may require more comparative studies. In some studies it is possible that we have used the wrong end points and quality of life and health status may be more important than lung function. In other studies beneficial effects for a few may have been overlooked in the analysis of group mean data. The role of inhaled steroids is becoming clearer. While a significant beneficial effect upon the rate of decline in airway calibre is unlikely, there is evidence that the rate of exacerbations may be reduced by their use. ${ }^{12}$ There may even be an effect on mortality, possibly using higher doses than are often used. $^{1314}$ More recently, study of the use of budesonide/formoterol ${ }^{15}$ and fluticasone/salmetero ${ }^{16}$ combinations in COPD have been shown to have some benefit on exacerbation rates and lung function.

This plethora of studies of the role of various pharmacological agents in COPD should not lull us into a sense of complacency. Most of these interventions achieve benefit of limited magnitude and the costs of the newer agents are always greater than their predecessors. We probably fail our patients by not calling more loudly for newer molecules to modify other aspects of the disease. Why should we expect anti-asthma therapies to be particularly useful for COPD? The focus for new medications should lie with control of the specific types of inflammation present in COPD and interventions that could aid in the reparation of damaged lung tissue would be ideal. We also need better antiviral remedies for viruses play a major part in the initiation of exacerbations of COPD. ${ }^{17}{ }^{18}$ The impact of exacerbations can be considerable and exacerbations are bad for you - 35 days after an exacerbation only $75 \%$ of patients had regained their original peak flow in one study and $7.1 \%$ had not returned to baseline at 3 months ${ }^{19} ; 30 \%$ of the elderly had still not regained mobility 3 months after discharge from hospital following an exacerbation and two thirds were unable to do housework they could previously do. ${ }^{20}$

We therefore need to think of new ways of helping to prevent exacerbations or to treat them promptly. Selfmanagement education for those with 
COPD has not been shown to alter outcomes. This does not reflect a lack of willingness of those with COPD to take control of their own disease; rather, it is likely to reflect a lack of efficacy of the interventions used and, in most of the studies, self-management for COPD has merely involved the use of an asthma self-management plan. What may be needed in COPD is a recognition that most exacerbations are associated with viral infections and, in addition to needing newer antiviral agents, we need more prompt use of antibiotics for secondary bacterial colonisation..$^{21} 22$

\section{"We need to augment the voice [of patients with COPD] and campaign against nihilism"}

When admitted to hospital with exacerbations we also fail these patients by the limited availability of non-invasive positive pressure ventilation (NIPPV). Despite overwhelming evidence of the benefit of this intervention, ${ }^{23}$ far fewer than the $16 \%$ of hospitalised exacerbations of COPD who are thought to need NIPPV actually receive it. ${ }^{24}{ }^{25}$ We also fail to realise that the timing of many exacerbations of COPD is predictable. The King's Fund in London has mapped very clearly both where demand for health service resources is likely to occur geographically within the London area and also the exact time of year at which such need is maximal. ${ }^{26}$ While we plan for surgical emergencies and major accidents, we rarely plan for peaks of demand for medical care, yet each year the admission of patients with COPD in the second or third week of January will stretch hard pressed hospitals.

There is probably little evidence that we fail our patients by a lack of prescriptions; where we may fail them is by over reliance on prescriptions of limited value and a failure to implement non-drug interventions. Pulmonary rehabilitation reduces symptoms and improves exercise tolerance and may be undertaken in hospitals, in the community, or at home. ${ }^{27-29}$ Encouragement to exercise is essential and may reduce the risk of exacerbations, ${ }^{30}$ and reinforcement of training may be needed after an interval. Sadly, too few patients are referred for pulmonary rehabilitation and, in the UK, where you live clearly dictates the pulmonary rehabilitation resources available to you. Many patients with COPD are also failed by not being adequately assessed for supplementary oxygen therapy, whether long term or during exertion. While oxygen is available long term by the prescription of oxygen concentrators and short term from cylinders, no provision is made in the UK for liquid oxygen or for small lightweight cylinders, nor for oxygen conserving devices, all of which might permit those with COPD to exercise more satisfactorily outside the home. In many parts of the country the availability of respiratory nurse specialists to ensure that those with COPD benefit maximally from what is available is also limited.

It is likely that we also fail our patients by a lack of appreciation of the effect of COPD upon quality of life, mood, and relationships. The late Trevor Clay, a nurse who died from COPD associated with an inherited condition, wrote: "Having a long term condition is not about dying - that only takes a few minutes or less-but I've been struggling to breathe for over 20 years and I've been living a lot and suffering as little as possible ${ }^{\prime \prime}{ }^{31}$ However, others are less able to be positive, and depression in this disease is common and often overlooked and undertreated. ${ }^{32}$

Dying from cancer or dying from motor neurone disease is unpleasant, but in the UK and in many other countries palliative medicine services and hospices relieve the worst of the discomfort, both physical and emotional. For those with end stage COPD the living death may be protracted, making it harder to know when to intervene with palliative measures, and the palliative measures themselves need dramatic improvement. Opiates may reduce the sensation of breathlessness, but the sedation they induce may be unpleasant for those with respiratory failure. We doubly fail our patients by our inability to modify the underlying disease and by our inability to discover new agents which satisfactorily modify the sensation of breathlessness. Little new seems to have been provided in this field since the work of Guz, Geddes, Woodcock and others 20 years ago. ${ }^{33-35}$

We all now have a responsibility to raise the profile of this disease-to prevent its cause, to modify its natural history, and to ensure the implementation of all measures, however small, that may reduce the suffering. We also need to call for more research for more effective interventions for both the disease and its symptoms. Those with COPD often also suffer socioeconomic deprivation. They do not have a loud voice. We need to augment their voice and to campaign against nihilism. If you smoke 30 cigarettes a day and have a myocardial infarction you receive sympathy, abundant health service resources, and research into heart disease is amply funded. If you have a similar nicotine dependence syndrome and develop COPD, few speak up for you, you are fortunate if you obtain the few interventions that might help, and research is poorly funded and not always directed at the key issues.

Thorax 2003;58:373-375

\section{Author's affiliation}

M R Partridge, Professor of Respiratory Medicine, Imperial College London, Faculty of Medicine, NHLI at Charing Cross Hospital, London W6 8RP, UK:

m.partridge@imperial.ac.uk

\section{REFERENCES}

1 Mannino DM, Buist AS, Petty TL, et al. Lung function and mortality in the United States: data from the First National Health and Nutrition Examination Survey follow up study. Thorax 2003;58:388-93.

2 World Health Organisation. WHO consultation on the development of a comprehensive approach for the prevention and control of chronic respiratory diseases. WHO/NMH/MNC/CRA/O1.1. Geneva: World Health Organisation, 2001.

3 World Health Organisation. Implementation of the WHO strategy for prevention and control of chronic respiratory diseases. WHO/MNC/CRA/02.2. Geneva: World Health Organisation, 2002

4 Doll R, Hill B. Smoking and carcinoma of the lung; a preliminary report. $B M$ 1950;2:739-48.

5 Fletcher CM, Peto R. The natural history of chronic airflow obstruction. $B M$ 1977; 1:1645-8.

6 Lundback $B$, Lindberg $A$, Lindstrom $M$, et al. Not 15 but $50 \%$ of smokers develop COPD? Report from the Obstructive Lung Disease in Northern Sweden Studies. Respir Med 2003;97:1 15-22.

7 Van Schayck CP, Loozen JMC, Wagena E, et al. Detecting patients at a high risk of developing chronic obstructive pulmonary disease in general practice: a cross-sectional case finding study. BM 2002;324:1370-3.

8 Kava T, Taylor J, Gamble E, et al. The availability of smoking cessation advice from health professionals: a census from one East London district. Respir Med 2000;94:983-4.

9 Pauwels RA, Buist SA, Calverley PMA, et al. Global strategy for the diagnosis, management and prevention of chronic obstructive pulmonary disease. Am J Respir Crit Care Med 2001;163:1256-76.

10 Vincken W, Van Noord JA, Greefhorst APM, et al. Improved health outcomes in patients with COPD during 1 year's treatment with tiotropium. Eur Respir J 2002;19:209-16.

11 Casaburi R, Mahler DA, Jones PW, et al. A long term evaluation of once-daily inhaled tiotropium in chronic obstructive pulmonary disease. Eur Respir J 2002;19:217-24.

12 Jones PW, Willits LR, Burge PS, et al. Disease severity and the effect of fluticasone propionate on chronic obstructive pulmonary disease exacerbations. Eur Respir $J$ 2003;21:68-73.

13 Soriano JB, Vestbo J, Pride NB, et al. Survival in COPD patients after regular use of fluticasone proprionate and salmeterol in general practice. Eur Respir $J$ 2002;20:819-25.

14 Sin DD, Man SFP. Inhaled corticosteroids and survival in chronic obstructive pulmonary disease: does the dose matter? Eur Respir J 2003;21:260-6

15 Szafranski W, Cukier A, Ramirez A, et al. Efficacy and safety of budesonide/formoterol in the management of obstructive pulmonary disease. Eur Respir J 2003;21:74-81.

16 Calverley P, Pauwels R, Vestbo J, et al. Combined salmeterol and fluticasone in the treatment of chronic obstructive pulmonary disease: a randomised controlled trial. Lancet 2003;361:449-56

17 Rohde G, Wiethege A, Borg I, et al. Respiratory viruses in exacerbations of chronic obstructive pulmonary disease requiring hospitalisation: a case-control study. Thorax 2003;58:37-42

18 Seemungal T, Harper-Owen R, Bhowmik A, et al. Respiratory viruses, symptoms, and inflammatory markers in acute exacerbations and stable chronic obstructive pulmonary 
disease. Am J Respir Crit Care Med 2001; 164:1618-23.

19 Seemungal TA, Donaldson GC, Bhowmik A, et al. Time course and recovery and exacerbations in patients with chronic obstructive pulmonary disease. Am J Respir Crit Care Med 2000;161:1608-13.

20 Peach H, Pathy MS. Follow up study of disability among elderly patients discharged from hospital with exacerbations of chronic bronchitis. Thorax 1981;36:585-9.

21 Patel IS, Seemungal TAR, Wilks $M$, et al. Relationship between bacterial colonisation and the frequency, character, and severity of COPD exacerbations. Thorax 2002;57:759-64.

22 White AJ, Gompertz S, Stockley RA. Chronic obstructive pulmonary disease $\cdot 6$ : The aetiology of exacerbations of chronic obstructive pulmonary disease. Thorax 2003;58:73-80.

23 Lightowler JV, Wedzicha JA, Elliott MW, et al. Non-invasive positive pressure ventilation to treat respiratory failure resulting from exacerbations of chronic obstructive pulmonary disease: Cochrane systematic review and meta-analysis. BM 2003;326: 185-7

24 Roberts CM, Lowe D, Bucknall CE, et al Clinical audit indicators of outcome following admission to hospital with acute exacerbation of chronic obstructive pulmonary disease. Thorax 2002;57: 137-4 1.

25 Roberts CM, Ryland I, Lowe D, et al. Audit of acute admissions of COPD: standards of care and management in the hospital setting. Eur Respir J 2001: 17:343-9.

26 The King's Fund. Managing the pressure. Emergency hospital admissions in London: 1997-2001. London: King's Fund Publishing, 2002

27 British Thoracic Society Standards of Care Subcommittee on Pulmonary Rehabilitation. Pulmonary rehabilitation. BTS statement Thorax 2001·56:827-34.

28 Bestall JC, Paul EA, Garrod R, et al. Longitudinal trends in exercise capacity and health status after pulmonary rehabilitation in patients with COPD. Respir Med 2003;97:173-80.
29 Morgan MDL. Preventing hospital admissions for COPD: role of physical activity. Thorax 2003;58:95-6.

30 Garcier-Aymerich J, Farrero E, Felez MA, ef al. Risk factors of readmission to hospital for a COPD exacerbation: a prospective study. Thorax 2003;58:100-5.

31 Clay T. How to keep the customer satisfied. Thorax 1994;49:279-80.

32 van Manen JG, Bindels PJE, Dekker FW, et al. Risk of depression in patients with chronic obstructive pulmonary disease and its determinants. Thorax 2002;57:412-6.

33 Mitchell, HP, Murphy K, Minty K, et al. Diazepam in the treatment of dyspnoea on the 'pink puffer' syndrome. Q J Med 1980;49:9-20

34 Johnson MA, Woodcock AA, Geddes DM Dihydrocodeine for breathlessness in pink puffers. BMU 1983:286:675-7.

35 Woodcock AA, Gross ER, Geddes DM. Drug treatment of breathlessness: contrasting effects of diazepam and promethazine in pink puffers. BM 1981;283:343-6.

\section{Usefulness of peak expiratory flow measurements: is it just a matter of instrument accuracy?}

\section{Brusasco}

A method for improving the accuracy of peak flow meters will be valuable if the recommendation to measure PEF is to be maintained in asthma management plans. With the currently available peak flow meters, no evidence has been provided that PEF measurements are of clinical usefulness. A large number of new randomised controlled studies using optimally validated peak flow meters would therefore be necessary. However, by that time these instruments may have become obsolete.

n this issue of Thorax Miller et al present a new method for validation of peak flow meters. They show that applying a computer driven explosive decompression can detect inaccuracies in the dynamic response of commercially available peak flow meters that would be missed using the ATS recommended 26 waveforms for spirometer validation. This work is justified by the compelling recommendations to use peak expiratory flow (PEF) as a main or sole measure of lung function, incorporated in the current guidelines for diagnosis and management of asthma..$^{2-5}$ In particular, PEF is recommended for daily home monitoring and also as a criterion for admission and discharge from the emergency room. For either application, accuracy of measurement is an obvious prerequisite. Indeed, previous works have shown that commercially available peak flow meters may not be accurate enough to allow correct management of a number of asthmatic subjects. ${ }^{67}$ As Miller et al ${ }^{1}$ correctly point out, a major clinical problem may arise from falsely high readings when underdamped peak flow meters are used, ${ }^{8}$ thus leading to potentially dangerous underestimation of the severity of airway obstruction.

In theory, an efficient way to monitor lung function in asthma should improve its management and clinical outcomes. This was the rationale that prompted an expert panel to recommend home measurements of PEF as a key component of action plans for asthma care. However, 10 years after the first introduction of asthma guidelines, evidence that home measurements of PEF flow with portable flow meters can substantially modify asthma management and outcomes is still lacking. Rather, the near totality of the randomised controlled studies so far published suggests the contrary. A recent Cochrane review of the available randomised controlled studies indicates that written action plans based on PEF are not superior to symptom based plans in the self-management of asthma in adults. ${ }^{9}$

Several reasons have been invoked to explain the lack of usefulness of PEF in asthma monitoring. Firstly, changes in PEF may not accurately reflect changes in airway function as assessed by more reliable measurements such as forced expiratory flow in 1 second $\left(\mathrm{FEV}_{1}\right)$ or forced vital capacity. Although discrepancies between PEF and $\mathrm{FEV}_{1}$ may in part be related to inaccuracy of portable flow meters, these two measurements may differ because of the greater sensitivity of PEF to upper airway function and the effects of expiratory effort, which depend on factors other than airway function including mood in nonsupervised self-assessment. ${ }^{10}$ Secondly, compliance with daily PEF measurements has been shown to be low and decreases with time. ${ }^{11}{ }^{12}$ A possibility exists that patients lack confidence in PEF because of its relative insensitivity to detect exacerbations compared with symptoms. ${ }^{13}$ This in turn may depend, at least in part, on the relative insensitivity of PEF to changes in airway calibre and on the inaccuracy of measurements, which may be ameliorated by using a more appropriate calibration procedure like the one proposed by Miller et $a l^{1}$ in this issue of Thorax. However, it is also possible that some patients are discouraged from using PEF because deep inspiration, which is required for its measurements, may cause ${ }^{14}$ or worsen ${ }^{15}$ bronchoconstriction. Whatever the reason, PEF data from diaries have been found to be unreliable because they have been incorrectly recorded or even fabricated, not only in subjects being studied 
for occupational asthma ${ }^{16}$ but also in children well motivated and informed about the importance of PEF measurements for adjustment of treatment. ${ }^{12}$

An argument in favour of PEF measurements is the possibility of detecting deterioration in airway function in a small proportion of asthmatic subjects who also perceive symptoms poorly. ${ }^{17}$ However, the available data suggest that changes in treatment are more likely to be undertaken by patients on the basis of symptoms than on changes in PEF. ${ }^{18}$ Furthermore, as PEF may decrease after the onset of symptoms, adjustment of treatment based on PEF may only delay appropriate treatment. ${ }^{13}$

The use of PEF as a guide for admission or discharge of asthmatic patients from the emergency room has not been proved. A recent nonrandomised prospective controlled study found that discharge of patients before complete resolution of symptoms and with PEF still below the recommended threshold did not increase the risk of early relapse. ${ }^{19}$ Furthermore, decisions on treatment adjustment or even emergency admission and discharge would vary greatly depending on whether the severity of an episode is defined using population based predicted or personal best values. ${ }^{20} 21$

Finally, recommendations for PEF use in asthma are mainly based on the assumption that PEF variability reflects, to some extent, airway hyperresponsiveness which is the key functional characteristic of bronchial asthma. This relationship was, however, found to be very weak. ${ }^{22}$ A recent community based survey has shown that indexes derived from PEF measurements are useless in detecting subjects with an established diagnosis of asthma, while the methacholine dose causing a fall in $\mathrm{FEV}_{1}$ of $20 \%$ is the best measurement of asthma. ${ }^{23}$

In conclusion, no evidence has so far been provided to justify the inclusion of PEF measurement in asthma management plans. This recommendation should therefore be removed unless it can be shown that improving the accuracy of peak flow meters also improves compliance and clinical outcomes. For this purpose a more suitable method for assessing the dynamic characteristics of the instruments, like the one elegantly described by Miller et al, ${ }^{1}$ may be valuable. The question is whether, by the time a sufficiently large number of new randomised controlled studies are completed, the peak flow meter will not become obsolete.

Thorax 2003;58:375-376

\section{Author's affiliation}

V Brusasco, Dipartimento di Medicina Interna e Specialità Mediche, Università di Genova, Viale Benedetto XV 10, 16132 Genoa, Italy;

Vito.Brusasco@unige.it

\section{REFERENCES}

1 Miller MR, Atkins PR, Pedersen OF. Inadequate peak expiratory flow meter characteristics detected by a computerised explosive decompression device. Thorax 2003;58:411-6.

2 Global Initiative for Asthma. Global strategies for asthma management and prevention. $\mathrm{NIHLBI} / \mathrm{WHO}$ workshop report 1993. Publication no. 95-3659. Washington: $\mathrm{NIH} /$ National Heart, Lung and Blood Institute, 1995.

3 National Asthma Education and Prevention Program. Expert panel report 2. Guidelines for the diagnosis and management of asthma. Publication no. 97-4051. Bethesda, MD: NIH/National Heart, Lung and Blood Institute, 1997

4 British Thoracic Society/Scottish Intercollegiate Guideline Network. British guidelines on the management of asthma. Thorax 2003;58(suppl I):i 1-94.

5 Canadian Asthma Consensus Report. Can Med Assoc J 1999:S1-62

6 Miller MR, Dickinson SA, Hitchings DJ. The accuracy of portable peak flow meters. Thorax 1992;47:904-9

7 Sly PD, Cahill P, Willet K, et al. Accuracy of mini peak flow meters in indicating changes in lung function in children with asthma. $B M$ 1994;308:572-4.

8 Miller MR, Pedersen OF, Quanjer PhH. The rise and dwell time for peak expiratory flow in patients with and without airflow limitation. Am J Respir Crit Care Med 1998;158:23-7.
9 Powell H, Gibson PG. Options for self-management education for adults with asthma (Cochrane Review). Cochrane Database Syst Rev 2003;CD004107.

10 Affleck G, Apter A, Tennen H, et al. Mood states associated with transitory changes in asthma symptoms and peak expiratory flow. Psychosom Med 2000;62:61-8.

11 Coté J, Cartier A, Malo JL, et al. Compliance with peak expiratory flow monitoring in home management of asthma. Chest 1998; 113:968-72.

12 Kamps AWA, Roorda R, Brand PLP. Peak flow diaries in childhood asthma are unreliable. Thorax 2001;56:180-2.

13 Chan-Yeung M, Chang JH, Manfreda J, et al. Changes in peak flow, symptom score, and the use of medications during acute exacerbations of asthma. Am J Respir Crit Care Med 1996;154:889-93

14 Pellegrino R, Violante B, Crimi E, et al. Time course and calcium dependence of sustained bronchoconstriction induced by deep inhalation in asthma. Am Rev Respir Dis 1991;144:1262-6.

15 Lim TK, Pride NB, Ingram RH. Effects of volume history during spontaneous and acutely induced air-flow obstruction in asthma. Am Rev Respir Dis 1987;135:591-6.

16 Malo JL, Trudeau C, Ghezzo H, et al. Do subjects investigated for occupational asthma through serial peak expiratory flow measurements falsify their results? J Allergy Clin Immunol 1995;96:601-7.

17 Fishwick D, Beasley R. Use of peak flow-based self management plans by adult asthmatic patients. Eur Respir J 1996; $9: 861-5$

18 Lahdensuo A, Haahtela T, Herrala J, et al. Randomised comparison of cost effectiveness of guided self management and traditional treatment of asthma in Finland. BM 1998;316:1 138-9.

19 Lim TK, Chin NK, Lee KH, et al. Early discharge of patients hospitalized with acute asthma: a controlled study. Respir Med 2000; 94: 1234-40

20 Douma WR, Kerstjens HA, Rooyackers JM, et al. Risk of overtreatment with current peak flow criteria in self-management plans. Dutch CNSLD Study Group. Chronic Non-Specific Lung Disease. Eur Respir J 1998;12:848-52.

21 Brenner DB, Camargo CA. Inaccuracy of "personal best" peak expiratory flow rate reported by inner-city patients with acute asthma. J Asthma 2001, 38:127-32.

22 Douma WR, Kerstjens HA, Roos CM, et al. Changes in peak expiratory flow indices as a proxy for changes in bronchial hyperresponsiveness. Dutch Chronic Non-Specific Lung Disease Study Group. Eur Respir J 2000;16:220-5.

23 Lewis SA, Weiss ST, Britton JR. Airway responsiveness and peak flow variability in the diagnosis of asthma for epidemiologica studies. Eur Respir J 2001;18:921-7. 